\title{
A IMAGEM DA INFÂNCIA NAS TESES DA FACULDADE DE MEDICINA DO RIO DE JANEIRO - (1832-1930) ${ }^{1}$
}

\author{
Adriana Amaral do Espírito Santo* \\ Ana Maria Jacó-Vilela \\ Marcelo de Almeida Ferreri"
}

\begin{abstract}
RESUMO. Este trabalho procura analisar historicamente o conceito de infância no Brasil e como a representação infantil passou de um papel secundário no sistema colonial a foco das preocupações no século XIX, através da atuação dos médicos higienistas. A partir da análise das teses de doutoramento da Faculdade de Medicina do Rio de Janeiro que discorrem sobre a criança, produzidas no período de 1832 a 1930, procuramos investigar de que maneira a construção e disciplina do corpo infantil se refletem no desenvolvimento de uma ciência psicológica. Neste percurso, deparamo-nos com discussões sobre temas que englobam não apenas o corpo, mas também a compreensão da alma infantil, sob a influência do paradigma científico e das teorias evolucionistas vigentes à época. Além disso, associada à imagem infantil, também encontramos a importância da mulher - enquanto mãe e ama - como mantenedora da família, constituindo uma nova moldagem também da figura feminina.
\end{abstract}

Palavras-chave: infância, medicina, psicologia.

\section{THE IMAGE OF CHILDREN IN THE THESES OF THE MEDICAL COLLEGE OF RIO DE JANEIRO (1832-1930)}

\begin{abstract}
This paper has the purpose to analyze historically the concept of childhood in Brazil. How the representation of children went from a secondary role during the colonization system to focus of concern in the $19^{\text {th }}$ Century, through the performance of Hygienist Doctors. In order to do so, we studied all the Theses of the Medical College of Rio de Janeiro, produced from 1832 to 1930 regarding children. By this study, we intended to search how the construction and discipline of the children's body are reflected in the development of a Psychological Science. Throughout the study, we found discussions on themes that involve not only the body, but also the comprehension of a child's soul, the predominance of a scientific paradigm and of evolutionist theories which were in effect at the time. Moreover, associated to the image of children, we also found the importance of women - while mother and wet-nurse - as a family keeper, composing a new model for the feminine figure.
\end{abstract}

Key words: Childhood, medicine, psychology.

A pesquisa histórica permite-nos compreender como diversos conceitos que hoje se encontram cristalizados foram, na verdade, construídos e desenvolvidos ao longo do tempo. Assim, além da desnaturalização de idéias, é possível também acompanhar o modo como estas são apropriadas em nossos dias, de maneira que os saberes psi da atualidade possuam alicerces sustentados não numa postura ingênua, mas em seus fazeres históricos. Da mesma forma, este ponto de vista facilita a elaboração de práticas futuras mais críticas e conscientes, evitando-se a manutenção daquelas que, situando-se fora de seu momento, representam presentificações e leituras equivocadas de eventos de outras épocas.

O presente trabalho procura seguir esta ótica, sendo parte constitutiva de pesquisa mais ampla que objetiva investigar a contribuição dos saberes católicos e médicos para o surgimento, autonomização e institucionalização da Psicologia em nosso país nos séculos XIX e XX. O interesse por esse assunto vem

1 Apoio Capes CNPq.

* Bolsista de iniciação científica CNPq.

\# Ph. D. pela Universidade Autônoma de Barcelona. Doutora em Psicologia Escolar e do Desenvolvimento Humano, USP-SP. Docente do Programa de Pós-Graduação em Psicologia Social da Universidade do Estado do Rio de Janeiro-UERJ.

Il Doutorando em Psicologia Social Universidade do Estado do Rio de Janeiro-UERJ. 
do entendimento de que a história do saber psicológico no Brasil não pode ser compreendida independentemente do contexto sociocultural, econômico e político em que o referido saber se insere e se desenvolve.

Sabemos que no período estudado - dentro do enquadre maior citado, trata-se de um recorte entre 1832 e 1930, cem anos que serão mais bem explicados posteriormente - as grandes profissões no Brasil resumiam-se ao Direito, à Engenharia e à Medicina. Dessa forma, as principais discussões sobre a vida em geral emergiam destes atores, que, localizados majoritariamente no Rio de Janeiro, então capital da nação - embora também presentes em São Paulo, Recife e Salvador - pretendiam dirigir o destino da sociedade, contrapondo-se, às vezes violentamente, aos senhores de terras, elite econômica desde sempre.

A intervenção médica nesse período ocorreu principalmente através da ação dos higienistas, encarregados de regrar os hábitos da família brasileira, em que permanecia a herança colonial, com ampla precarização do modo de vida. Coube a eles implementar novas normas de educação física, moral, intelectual e sexual, de maneira a cultivar na população o gosto pela saúde, modificando a concepção desta em todos os níveis (Costa, 1999). Especialmente, a Medicina se dedicou ao tratamento da infância, parcela da sociedade que foi alvo de várias de suas produções.

Esta ação intensa funcionou como uma poderosa forma de normalização e controle da sociedade, substituindo lentamente o discurso católico predominante até então, embora não necessariamente renegando seus valores. Através desta intervenção, a Medicina desenvolveu diversos temas, muitos dos quais hoje situamos na área de Psicologia, em suas mais variadas abordagens.

Partindo deste raciocínio, tomamos como foco deste trabalho as diferentes imagens da infância que se apresentam nas teses da Faculdade de Medicina do Rio de Janeiro. Sabemos que a proposição racional de ciência não pôde deixar de utilizar imagens diversas (Durand, 1998). No caso do período oitocentista brasileiro, estas decorrem, por exemplo, do imaginário religioso ainda pregnante, apesar do materialismo professado pelos "homens de ciência" (Schwarcz, 1993). E ressurgem a cada momento, em metáforas escolhidas, expressões com forte sentido conotativo, artifícios de linguagem.

São imagens que sintetizam valores, gostos, ideais, condutas. Nem sempre icônicas e muitas vezes decorrentes da linguagem oral ou escrita, são construções baseadas nas representações elaboradas por determinada sociedade em um momento peculiar de sua história. No caso específico que aqui nos interessa, o caráter das imagens de infância decorre, sem dúvida, do hibridismo proveniente da tradição colonial e do cientificismo que se esmeram em apresentar as teses da Faculdade de Medicina. Tais teses são, assim, "efeito de complexa rede" (Díaz, 1996, p. 13) e nos apresentam crianças, mães e amas, possibilitando uma construção da noção de infância da Medicina higienista.

Neste texto, nosso primeiro ponto será apresentar a imagem da infância no Brasil-Colônia; em seguida, explicaremos o funcionamento e a importância das teses da Faculdade de Medicina do Rio de Janeiro. Como terceiro ponto, e corpo principal deste trabalho, analisaremos, através de uma "galeria" de imagens retiradas das referidas teses, como a representação da criança foi sendo cuidadosamente moldada na sociedade oitocentista brasileira. Finalizaremos apontando a impossibilidade de dissociar essa moldagem da construção de uma nova figura feminina.

\section{A IMAGEM DA INFÂNCIA NO BRASIL- COLÔNIA}

A representação da criança durante os primeiros séculos de colonização do Brasil seguiu os moldes ditados por Portugal, mantendo estreita relação com a doutrina da Igreja Católica. Logo após o descobrimento, como forma de driblar a grande dificuldade em converter e educar o gentio, o principal meio de evangelização dos nativos foi o trabalho dos padres, principalmente jesuítas, sobre a infância brasileira (Massimi, 1990). A solução encontrada pelos portugueses foi, pois, a ação direta sobre as crianças, que, devidamente domesticadas, transmitiriam os ensinamentos da catequese e os modos de conduta europeus ao seu povo.

Uma vez que, além de educadores, os jesuítas também faziam o papel de médicos, farmacêuticos e enfermeiros (Carneiro, 2000), seu trabalho ditou a pedagogia que vigorou durante séculos. A chamada "medicina da alma" refletia a mentalidade do direito auto-atribuído aos povos "civilizados" de evangelizar aqueles considerados seus inferiores, os quais deviam ser seus protegidos; assim, tornavam-se fiéis, escravos ou trabalhadores (Arantes, 1995).

O período colonial refletiu, ainda segundo Arantes, uma grande desvalorização da criança, que, se escrava, era tratada como mercadoria, e, caso órfã 
ou exposta, era entregue à Roda dos Expostos ${ }^{2}$ e conduzida ao trabalho precoce e explorador (Arantes, 1995). Mesmo a criança da elite ocupava uma posição secundária na família, pois se encontrava a serviço do pai, que detinha poder ilimitado sobre seus filhos (Costa, 1999).

Lembramos que o catolicismo português era muito pouco "racional", estando eivado de práticas místicas (Sanchis, 2000). Assim, a sabedoria transmitida pelas avós, o temor a Deus, a reprodução de costumes herdados dos europeus - em nada adequados ao clima tropical -, acrescidos das práticas trazidas pelos escravos africanos, contribuíram para um elevado índice de mortalidade infantil nos primeiros séculos de Brasil.

De acordo com Costa (1999), para o catolicismo a criança só tinha relevância como sinal de pureza e inocência, sendo comumente representada sob a forma de anjo. Esta visão funcionava de modo que a alta incidência de morte desses pequenos "anjinhos" pudesse ser, então, venerada, principalmente pelas mães, que, com o beneplácito e mesmo incentivo da Igreja, viam no falecimento de seus filhos a certeza da felicidade para eles e a perspectiva de um reencontro sublime quando elas próprias morressem.

Esta forma de compreensão do mundo infantil, aliada à hegemonia do poder paterno, do patrimônio e da religião, ofuscava a vida da criança enquanto etapa do desenvolvimento humano - como concebido posteriormente -, sendo a mesma percebida em oposição ao adulto, e por isso carente de qualidades. Assim, a criança era distanciada, em seus tenros anos, do mundo adulto que a envolvia, consistindo a infância apenas em um estado larvar do adulto, incompetente e em miniatura, até que alcançasse a maturidade. $\mathrm{Na}$ verdade, interessava ao pai criar seus filhos de modo que fossem capazes de, muito cedo, assumir os negócios da família, o que Costa chama de "adultização" da infância (Costa, 1999, p.159). Assim, somente quando atingia a idade considerada ideal para os negócios é que aquele indivíduo tornava-se visível para a família e a sociedade.

Por outro lado, como desdobramento da hegemonia jesuítica, mesmo após uma maior

\footnotetext{
A Roda foi criada para tentar garantir o anonimato da pessoa que abandonava a criança nas Casas de Expostos, dessa forma assegurando também a assistência dos órfãos e buscando diminuir o índice de mortalidade infantil. Consistia num dispositivo cilíndrico em que a criança era depositada pelo lado de fora e, por um movimento rotatório, deixada do lado de dentro da Casa, sem que se soubesse a identidade de seu expositor (Costa, 1999; Arantes, 1995).
}

participação do Estado na assistência à população, ainda predominavam as instituições de caridade ou aquelas estreitamente vinculadas ou mesmo administradas pela Igreja, como as Santas Casas de Misericórdia. Apenas no início do século XIX, tendo como marco principal a vinda da Corte Portuguesa para o Brasil, em 1808, algumas instituições laicas começaram a ganhar espaço (Schwarcz, 1993).

A chegada da Família Real significou principalmente o surgimento de dispositivos e interesses que visavam adaptar a cidade do Rio de Janeiro, onde a Corte se fixara, aos hábitos do grande contingente europeu recém-chegado - mais de 15 mil pessoas. O carro-chefe desta mobilização foi a atuação dos médicos higienistas, que compreendiam como sua obrigação o enquadramento das camadas mais ricas nos modos de conduta que pretendiam que fossem seguidos pela população, objetivando a proximidade da cidade/país ao modelo civilizado europeu (Costa, 1999).

Baseados na cientificidade de seus estudos, os médicos foram gradativamente mergulhando a sociedade em regras e recomendações, sem dúvida, modernas para a época, completamente diferentes das práticas do período colonial, em que predominava o saber familiar tradicional. Essas modificações só foram possíveis com a emergência de novos conceitos relacionados à infância, incluindo noções de evolução, diferenciação e gradação, heterogeneidade e continuidade (Costa, 1999). Ou seja, serão necessárias muitas mudanças sociais e econômicas - como os movimentos republicano e abolicionista -, coroadas pela entrada em cena da teoria evolucionista, para que a infância seja percebida como um estágio anterior à vida adulta.

Dessa forma, a visão da infância como uma etapa biológico-moral do desenvolvimento, antes inexistente, ganha contornos cada vez mais nítidos. Nesse momento, tanto a infância quanto a adolescência começam a ser vistas como idades da vida que representam momentos de transição e esperança (Del Priore, 2000). A temática da criança passa a servir também como forma de cultivar, desde o nascimento, o sentimento de nacionalidade dos indivíduos. Aos poucos, a criança pobre deixa de ser apenas objeto de caridade e passa a ser objeto de políticas públicas (Arantes, 1995).

Assim, a Puericultura e a Pediatria fundamentam campanhas de intervenção médica nas famílias, abordando os períodos de pré-fecundação, intra e extra-uterino (Arantes, 1995). Ou seja, cuidam desde a regulação da vida em sociedade, que implicava as características físicas, morais e intelectuais dos 
candidatos ao matrimônio, até os cuidados durante a gestação, parto, puerpério e a vida da criança em seus primeiros anos.

\section{AS TESES DA FACULDADE DE MEDICINA DO RIO DE JANEIRO}

A chamada "intervenção médica na sociedade" reflete-se no discurso que emergia da Faculdade de Medicina do Rio de Janeiro, através de suas teses de doutorado $^{3}$, parte empírica substancial da pesquisa que estamos desenvolvendo.

Tais trabalhos consistiam, na verdade, em dois tipos: uma pequena parte de "teses" apresentadas em concurso para professor da Faculdade de Medicina; a grande maioria de trabalhos de conclusão do curso, semelhantes às monografias que são produzidas atualmente, com a diferença de falarem sobre os mais variados temas e poderem chegar a dezenas de exemplares. Estes trabalhos de fim de curso tornaramse obrigatórios quando da transformação dos antigos cursos de Cirurgia em Faculdades de Medicina do Rio de Janeiro e da Bahia em 1832 e permanecem nesta condição até a reforma do ensino médico ocorrida em 1930, motivo pelo qual centramos nossa investigação nestes cem anos.

Em nossa pesquisa, a consulta deste material foi realizada em três lugares, todos situados no Rio de Janeiro: a Biblioteca do Centro de Ciências da Saúde da Universidade Federal do Rio de Janeiro (UFRJ), a Academia Nacional de Medicina e a Biblioteca Nacional, tendo em vista que em nenhum destes encontra-se depositada a totalidade das teses produzidas.

Dentre as quase dez mil teses realizadas no período citado, procedemos à seleção daquelas que, de acordo com análise inicial de seus títulos, poderiam possuir algum conteúdo psicológico. Posteriormente estas foram agrupadas em categorias e subcategorias, sendo lidas aproximadamente $20 \%$ das teses de cada subcategoria. Este procedimento, de validação da escolha original por título, permitiu que fossem resumidas aquelas em que se comprovava, após leitura atenta, a presença de argumentação de teor psicológico. Tivemos necessidade, então, de proceder à revisão de algumas categorizações, em vista de o conteúdo expresso no texto não ser exatamente o sugerido pelo título.

3 O termo doutorado é utilizado aqui no sentido de conclusão da Faculdade de Medicina, e não como se entende hoje, um título adquirido após a conclusão do curso de pós-graduação.
As 44 teses que discorrem sobre a criança encontram-se agrupadas na categoria Infância e Desenvolvimento, subdividida em 11 subcategorias. Entretanto, neste momento, optamos por analisar somente as teses de cinco subcategorias: Educação dos Expostos, Educação Física, Educação Global, Higiene e Higiene e Educação. Esta escolha se deve ao fato de que tais subcategorias podem ser agrupadas como se referindo a Higiene e Educação, e nos parecem indicar serem as teses em que mais se expressa uma imagem de infância, tanto a imagem que se quer extirpar quanto aquela que se pretende alcançar.

\section{A IMAGEM DA INFÂNCIA NAS TESES DE MEDICINA}

Qual a imagem que emerge das teses? Em primeiro lugar, cabe observar que suas temáticas eram indicadas pela Faculdade. Assim, em um dado ano encontramos muitas teses sobre o mesmo assunto, freqüentemente com o mesmo enfoque, o que nos permite supor que se trata de conhecimento compartilhado, da "ciência comum" (Kuhn, 1997) compartilhada por professores e estudantes. Em segundo lugar, deve-se recordar que os médicos se encontravam imbuídos de um espírito missionário, da idéia de que cabia aos "homens da ciência" (Schwarcz, 1993) a resolução dos problemas que impediam o país de assumir um lugar junto às nações civilizadas, percepção que sem dúvida influenciava as escolhas de temas pela Faculdade. Vamos, então, apontar alguns traços desta imagem da infância que as teses nos fornecem.

"A adolescência, a infância, os dez primeiros anos em particular constituem a idade de ouro da higiene mental"' (Lima, 1927, p.11)

Desde as primeiras teses, a ciência aparece como base do estudo e atuação médica junto à sociedade, particularmente com relação à infância. Nesse sentido, percebe-se um esforço de aprofundamento científico do discurso, que tem como conseqüência um novo olhar sobre o ser humano. Por exemplo, se antes, como vimos em relação ao período colonial, os primeiros anos de vida eram negligenciados, neste segundo momento é crescente o interesse e a compreensão da necessidade de conservação da vida da criança, com maior cuidado relativo à diminuição da mortalidade infantil - afinal, esta é a "idade de ouro", podemos subentender que não só da Higiene, mas da própria vida humana. 
O crescimento humano adquire uma divisão cronológica, embora ainda não categórica, as datas diferindo um pouco de autor para autor. De qualquer forma, a noção de "períodos do desenvolvimento" abre espaço para condutas e tratamentos determinados de acordo com as condições fisiológicas do organismo em cada estágio, com cuidados específicos para cada faixa etária. Assim, encontramos, na tese de Machado, de 1875, a sugestão sobre o tipo de assistência ideal para a criança, desde a recém-nascida, quando deveria ser abrigada do frio e da umidade, passando pela infância (dos sete dias de vida aos dois anos), até a segunda infância (que culmina na puberdade ${ }^{4}$ ), numa exposição gradativa às atividades sociais e às características do meio.

As diferentes fases do desenvolvimento humano durante a infância surgem com fundamento no evolucionismo spenceriano adotado pelos médicos, e ao mesmo tempo embasam os princípios de higiene mental a que estes vinham se dedicando desde meados do século XIX. É principalmente nas teses do início do século XX, contudo, que a higiene mental aparece mais bem-delineada, estruturando e sendo sustentada por outras ciências, como a Pedagogia e a Psicologia, num discurso mais claro e sólido, como o que aparece na tese de 1927, citada acima e utilizada como primeira pincelada deste retrato que estamos constituindo.

\section{"Bela e ardente fase da vida, a puberdade é rodeada de sérios perigos" (Machado, 1875, p.29)}

Dentro da idéia de escala evolutiva que começa a sustentar o pensamento médico, a criança representa, pois, o adulto em formação: "ela é a miniatura, o microcosmo do adulto, com todas as boas e más qualidades em estado embrionário" (Dr. Valentim Magalhães, citado por Fernandes, 1903, p.5) .

Da mesma maneira, enfatiza-se a presença dos caracteres hereditários, a acentuar que, muitas vezes, mesmo a melhor educação moral, intelectual e física

4 Aparentemente, os autores não fazem uma diferenciação entre puberdade e adolescência, empregando ambos os termos muitas vezes como sinônimos. Lima (1927), por exemplo, estipula a adolescência entre 7 e 14 anos, referindo-se mais adiante ao mesmo período como sendo "puberdade". Embora às vezes estes termos sejam utilizados em relação a períodos de mudanças orgânicas, outras vezes se referem à fase de vida escolar, como aparece no citado Lima.

5 Maria da Glória Fernandes foi uma das primeiras mulheres a se formar na Faculdade de Medicina do Rio de Janeiro, sendo sua tese a primeira, de autoria feminina, onde encontramos teor psicológico explícito. nada pode fazer por determinados indivíduos, comprometidos quiçá por sua herança.

De qualquer forma, fechando esta fase inicial do homem, está a puberdade, momento de maior risco nos conflitos entre razão e emoção: "é na puberdade que os caracteres se acentuam, que a inteligência atinge ao seu completo desenvolvimento e que a bela e perigosa faculdade de criar imagens solta o vôo no mundo das fantasias" (Machado, 1875, p. 28). Mais adiante, o autor continua: "Bela e ardente fase da vida, a puberdade é rodeada de sérios perigos. É então que os vícios, quase sempre já adquiridos na infância, sufocam a razão nascente, e assumem, tantas vezes, completo domínio sobre o indivíduo, qualquer que seja o sexo, sempre com grave detrimento físico, intelectual e moral do infeliz jovem" (Machado, 1875, pp.29-30).

É interessante observar que, a par da manutenção da importância de caracteres hereditários ou endócrinos próprios da puberdade, o autor aponta também os fatores ambientais, a má educação na infância podendo levar a criança a ser dominada pelos vícios. Daí todo o cuidado que se atribui à educação durante os primeiros anos de vida e à necessidade de manutenção de um ambiente harmonioso, sadio e higiênico ao seu redor durante toda a vida.

“Aproveitar as primeiras épocas da vida, em que é mais fácil amoldar essa cera mole, como já o disse alguém, aos atos, é um grande passo para o fim a que se propõe a educação" (Barbosa, 1882, p. 39)

A atuação médica, marcando o predomínio da ciência sobre a tradição doméstica, priorizou a ação junto ao seio familiar. Assim como os jesuítas recorreram à catequização infantil para atingir os adultos, também os médicos do Brasil oitocentista enxergaram nas crianças, "soldados da saúde" (Costa, 1999, p.204), o caminho para alcançar os outros membros da família e, principalmente, a semente para se chegar, num futuro próximo, à imagem do adulto adequado para a sociedade brasileira que se almejava construir - civilizada, européia, branca.

Como fundamento dessa intenção estava a idéia da criança como uma "cera" onde se imprime a forma desejada, que é conservada durante muitos anos

6 A tese Higiene da primeira infância, de autoria de Adolfo Alves Simões Barbosa, 1882, não foi encontrada por nós em nenhum dos locais de pesquisa. Por este motivo, todas as citações utilizadas aqui foram retiradas do livro Ordem médica e norma familiar, de Jurandir Freire Costa, edição de 1999. No entanto, optamos por manter a referência, no decorrer do texto, ao autor original, para que ficasse explícito tratar-se de conteúdo de uma tese. 
(Mello, 1846). Uma vez que é aberta a todas as impressões do mundo, é de importância crucial cuidar do ambiente à volta da criança, particularmente das pessoas que estão em convívio direto e diário com ela. Ou seja, aqui a ênfase afasta-se decisivamente dos fatores hereditários para os ambientais.

Seguindo este raciocínio, a atuação higienista recaiu sobre a mulher, colocando em prática uma reformulação da conduta feminina com relação aos filhos, através da educação física, moral e intelectual:

Se quiserem que a educação tenha influência decisiva e completa nos destinos de um país, diz Bordier, que a educação seja verdadeiramente o meio social por excelência, capaz de engrandecer o futuro dos cidadãos, é da educação da mulher, que mais importa cuidar (Fernandes, 1903, p.54).

"Vesti-vos, alimentai-vos regradamente e compenetraivos desta verdade que sois esposas, mães, e que sois mais a alma de vossas famílias do que das sociedades" (Ubatuba, 1845, p. 22).

A Medicina de fins do século XIX e início do XX demonstra uma tendência a designar à mulher o papel principal na educação dos filhos, enquanto os pais funcionariam mais como provedores de recursos materiais, como bem afirmou Barbosa:

Recebendo do pai a proteção material e da mãe a iniciação na Educação, o infante prepara-se física, intelectual e moralmente para amar e servir à Humanidade, princípio e fim de suas operações (Barbosa, 1882, p.14).

Em 1903, na tese de Fernandes, a mesma imagem prevalece. A autora afirma que a mãe é o "primeiro e mais seguro mestre" da prole - ou seja, a "alma", o centro da vida familiar -, exercendo autoridade sem limites e influindo mais do que o pai sobre as ações dos filhos (Fernandes, 1903, p.53).

Entretanto, para Armonde (1874), a mulher não poderia deixar de receber educação moral, o que denota a necessidade de um controle rígido sobre aquela que, por seu dever sublime de mãe, exerce enorme influência sobre o homem. Este pensamento nos parece estar estreitamente relacionado à imagem de mulher pecadora e vulnerável às "paixões d'alma", resquício ainda decorrente do predomínio da Igreja Católica durante tantos séculos, pois verificamos que o discurso das teses está permeado de idéias relacionadas à doutrina cristã, como em Santos (1857, p.24): “... a mulher é filha de Eva; (...) o ouvido sempre inclinado à sedução...".
Assim, as bases da educação moral feminina estão presentes em diversas teses, como em Veiga Sobrinho (1886) e Santos (1857), orientando desde as vestimentas mais adequadas até as condutas que deveriam ou não ser adotadas perante a sociedade, de modo a construir uma base sólida para as famílias.

\section{"É desde o aleitamento que a educação moral da criança começa". (Santos, 1857, p. 57)}

Seguindo o raciocínio da necessidade de educação moral da mulher pecadora, não apenas a criança, mas também os adultos responsáveis por ela foram invadidos por inúmeras regras higiênicas e educacionais, visando principalmente à profilaxia dos males que a sociedade, ainda rudimentar, longe dos patamares civilizados, podia acarretar. As recomendações diziam respeito não só ao controle de fatores ambientais nocivos, mas também à regulação da vida das mães e amas, visto que, além de doenças, também as características perniciosas e os maus hábitos poderiam ser transmitidos tanto geneticamente quanto através do aleitamento. Exemplo disso é a nota presente na tese de Ubatuba: "Al-Doune nos seus conselhos às Mães, recomenda-lhes, que não dêem seu peito quando tenham algum motivo de cólera senão passados alguns minutos" (Ubatuba, 1845, p. 23 - nota de rodapé). Ubatuba reproduz um pensamento expresso por muitos outros autores: a idéia de que os estados emocionais, mesmo aqueles circunstanciais, provocados, por exemplo, por um susto, influenciavam a qualidade do leite, prejudicando a nutrição da criança pela transmissão de caracteres nocivos.

Este pensamento está presente também na tese de Santos (1858), para quem

as afecções morais e a irritação nervosa das amas têm uma grande influência sobre a nutrição das crianças; mas esta influência, longe de ser constante, é considerada como excepcional. As emoções de toda sorte, as contrariedades violentas, os profundos desgostos, em geral todas as paixões, modificam rapidamente a composição do leite e o tornam nocivo (Santos, 1858, p. 44).

Mais adiante, o autor continua:

... certas disposições do coração, as afecções morais, as paixões e algumas moléstias crônicas e agudas que não são acompanhadas de uma modificação do leite, têm todavia uma influência muito grave sobre a saúde da criança (...). O medo, os desgostos, a cólera, as amofinações continuas, são algumas vezes a 
causa de perturbações assaz graves (...). As convulsões na criança, as mais das vezes são as manifestações de que o seu mal proveio de uma paixão violenta ou de se ter dado com excesso a prazeres venéreos (Santos, 1858, p.47).

“o aleitamento natural da criança é o leite”. (Duque, 1864, p. 23)

A amamentação constituiu, assim, um dos temas centrais do discurso médico. As mães, em sua maioria muito jovens, eram incumbidas do aleitamento, contrariamente à regra anterior de deixar a amamentação por conta das escravas amas-de-leite.

A campanha pelo aleitamento materno é explícita e embasada nos pressupostos científicos. É interessante observar que a crença na capacidade científica está tão arraigada nesse momento que é possível até mesmo um ato de humildade. Um dos argumentos da campanha pró-aleitamento materno é o reconhecimento dos limites da ciência, pois nem mesmo ela conseguiria encontrar um substituto para o poder natural do leite materno. Daí a condenação moral daquela mulher que, apenas pela vaidade e ignorância, abstém-se de amamentar seu filho, contrariando mesmo seus próprios instintos:

... o leite é, pois, incontestavelmente aquele que a natureza destinou ao recém-nascido, e o substituí-lo seria ir de encontro ao voto desta, e diminuir a humanidade. Já não é pouca violação a que a necessidade, o capricho, a ignorância, a frivolidade ou as considerações do bem-estar individual impõem, trocando o seio materno por um seio alheio ou pela teta de um animal; e estamos certo que se muitas mães, nas quais só a vaidade abafa os santos instintos e deveres da maternidade, pudessem bem se compenetrar das vantagens que resultam seus filhos, alimentando-os do leite materno, de um lado, e de outro, dos inconvenientes a que ficam expostos, entregando-os á uma ama para dela ou de um animal receberem a nutrição, estamos certo, dizemos, que essas mães fariam depressa o sacrifício de seu bem-estar individual, de seus divertimentos, e de suas pretensões á beleza e á mocidade para se prestar de boa mente a cumprir a sublime missão que lhes confiou a natureza. Ninguém é mais sábio do que esta grande mestra: em vão busca a ciência, estudando o menino e o leite, achar entre estes dois termos a exata relação que ela estabelece por meio de seus processos misteriosos. A ciência aproxima-se mais ou menos dessa relação em suas louváveis tentativas, mas, não a atinge, e se, por acaso, o consegue uma ou outra vez, - impotente - permanece no maior numero delas aquém ou vai além.” (Duque, 1864 , p. 23-24).

As "tentativas da ciência" com relação ao tema do aleitamento materno aparecem nas teses, como em Duque (1864), Santos $(1857,1858)$, através da descrição anatomofisiológica dos órgãos vitais, dimensões, peso, pele dos recém-nascidos, e também sob a forma das inúmeras tabelas comparativas entre os leites de animais entre si - em geral, de vaca, cabra, ovelha e jumenta - e desses com relação ao humano. As análises consideravam a quantidade, composição, alterações, riqueza e pobreza do leite, bem como diferenciavam essas características no leite da mulher em seus diferentes estados: sua idade e a do leite, constituição, estado de menstruada, condição de primípara ou multípara.

$\mathrm{Na}$ tese de Santos (1857) é interessante notar a clara entrada de instrumentos recém-desenvolvidos com o auxílio da ciência, como métodos de controle da qualidade do leite. $\mathrm{O}$ autor recomenda o uso do microscópio, do lactômetro e do lactoscópio, por serem mais seguros na verificação da qualidade, em detrimento do método então utilizado de provar o leite ou de colocá-lo no fundo de uma colher e observar o que sobra quando é entornado. Este mesmo autor cita ainda, em seu trabalho, o resultado de uma experiência realizada sobre as condições do aleitamento em cães. Enfim, o discurso científico e a tecnologia dele decorrente encontram-se cada vez mais presentes, levando a que aqueles métodos baseados na tradição e na experiência humanas fossem pouco a pouco preteridos pelos mais modernos e científicos.

Observe-se que este discurso, inicialmente apontando as vantagens do leite materno e o caráter quase sagrado da função de amamentação, caminha gradativamente para uma culpabilização da mãe que não amamenta. Assim, quase ao final do século, Martins (1882) afirma que a mãe que não amamenta seu filho é criminosa ou infeliz. No primeiro caso, é uma mãe má; no segundo, sofre por essa impossibilidade, seja por insuficiência do leite seja porque trabalha o dia todo.

"[a ama deve ser] moça, nascida de pais sadios, gozando perfeita saúde, bem desenvolvida, tendo bons dentes, seios não mui volumosos com os bicos bem formados, de boa conduta e caracter, de uma inteligência, mais ou menos esclarecida, não ser muito impressionável e nervosa". (Santos, 1858, p. 32)

Eram poucos os casos que permitiam o aleitamento por outras formas que não o materno. Como observa Duque (1864), essas decorriam de impedimentos de ambos os pais (vícios hereditários e 
consangüinidade de moléstias); do estado de abandono da criança (estas, geralmente recolhidas pelas Casas de Expostos); mas principalmente de uma característica da mulher, como sua constituição debilitada, moléstias como tuberculose, cancerismo, escrófulas, sífilis, vício gotoso, alienação, epilepsia, deformação do bico do seio, moléstias locais na glândula mamária. Nestes casos, recorria-se geralmente às amas - mulheres pobres, ex-escravas ou mesmo escravas servindo aos seus senhores.

Devido a tais origens das amas, havia uma lista de prescrições para sua seleção e convívio com a criança, entre as quais a observação de diversas características físicas, mentais e principalmente morais era de grande relevância. Além dos atributos citados anteriormente e da confirmação da não-existência de condições impeditivas, eram verificados também o estado dos dentes, dos seios, além de hábitos e das características de seu leite. Inúmeras destas recomendações aparecem nas teses de Pacheco e Costa (1840), Pederneira (1855), Santos (1857) e Santos (1858), entre outras.

De acordo com Ubatuba, esse cuidado com relação à saúde, bom caráter e inteligência das amas, deveria existir "não só para que as crianças não herdem as enfermidades d'elas, como para que sejam bem tratadas" (Ubatuba, 1845, p. 22). Este autor demonstra preocupação e recomenda vigilância cuidadosa mesmo das amas de confiança, para que não fizessem mal à criança de nenhuma forma, inclusive através de seus contos e histórias.

"o vicio, a vergonha ou a miséria que atiram á roda de uma casa de expostos ou á praça pública um infeliz..." (Duque, 1864, p.4)

Os médicos produziram muitos trabalhos com relação ao problema da exposição de crianças em locais públicos ou nas Rodas, preocupados com o futuro dessas “infelizes" órfãs. Nesse sentido, a valorização do papel da mulher enquanto mãe se apresenta também no discurso relativo às crianças entregues a essas instituições.

Para Santos (1857, p. 22), a mulher que abandona seu filho é uma "pedra". Podemos entender esta expressão tomando como base o próprio discurso das teses, onde a metáfora é freqüente. Assim, Pederneira, sob essa mesma ótica, reforça a idéia de desvirtuamento e frieza da mulher que abandona seu filho, condenando veementemente a exposição de crianças: "quando se dá a abnegação do mais santo e puro dos sentimentos naturais, o amor de mãe, tem-se tocado ao cúmulo da imoralidade" (Pederneira, 1855, p. 20). O traço do retrato infantil aqui será, claramente, a infelicidade estampada no rosto das crianças abandonadas.

"se encontra nas habitações da gente pobre tudo quanto podemos encontrar nos hospícios de inconveniente para a criação dos expostos, sem encontrarmos o que há de favorável nestes últimos" (Santos, 1857, p.33)

No que diz respeito à administração das amasde-leite nas Casas de Expostos, os problemas encontrados se revelavam ainda maiores. A questão principal era a dúvida quanto ao melhor regime de criação dos expostos - se dentro desse tipo de estabelecimento ou se em casas de amas. Por um lado, os asilos ${ }^{7}$ apresentavam índices alarmantes de mortalidade, pois eram construídos fora dos padrões higiênicos, com acúmulo de pessoas num mesmo cômodo, inclusive misturando-se os doentes e os sãos. Entre esses e outros problemas, estava também, segundo Pederneira (1855), a privação do carinho maternal.

Para os médicos que eram a favor da criação nas Casas de Expostos, contudo, era a Higiene que faria a diferença, pois era vista então como meio fundamental de atenuação daqueles inconvenientes:

Se a cifra dos meninos enjeitados, e educados
à custa da sociedade, cresceu tão
prodigiosamente, há trinta anos, não é porque
de ano a ano haja um número maior de
meninos expostos e enjeitados; é porque
morrem muito menos, graças às aplicações
felizes da higiene pública á educação das
crianças (Santos, 1857, p. 24).

No entanto, a criação externa também tinha seus problemas. Segundo Santos (1857), as pessoas, em geral pobres, que pegavam crianças nos hospícios para educar, recebiam uma quantia irrisória do governo, não podendo dar-lhes o tratamento conveniente. Por isso, a criação externa poderia ser de pior qualidade do que a das Casas. E como havia grande facilidade para pegar crianças expostas para criar, não havia o cuidado devido à sua tenra idade, contribuindo para o elevado índice de mortalidade. O discurso de Santos (1858), por exemplo, critica as amas que só criavam expostos

\footnotetext{
Os autores das teses empregam indistintamente os termos "asilo" e "hospício". No entanto, é bom esclarecer que o termo "hospício" era utilizado até então para indicar os estabelecimentos que abrigavam os diferentes tipos de dejetos sociais - loucos, órfãos, mendigos, vagabundos, doentes graves. Somente com a institucionalização do conceito de doença mental é que "hospício" assumirá o sentido de "local para tratamento de loucos".
} 
visando à recompensa monetária, pois negligenciavam o cuidado com essas crianças, não raramente substituindo a amamentação por outro tipo de alimento e não chamando um médico em casos de doença. Para este autor, o médico só era chamado na iminência da morte da criança, para que o atestado de óbito garantisse o direito de recolher outro exposto para criar. Ainda segundo Santos, no caso de as amas serem escravas, muitas vezes o ato do aleitamento era realizado com indiferença, apenas em obediência a seus senhores, o que colocava em dúvida sua moral e também arriscava a vida das crianças.

Não obstante, de acordo com Pederneira (1855), muitos senhores de escravos ou mesmo mães colocavam as crianças nas Casas de Expostos para depois se proporem a criá-las, recebendo o pagamento do governo ou da Santa Casa por esta atividade.

\section{CONSIDERAÇÕES FINAIS}

Como foi visto, a infância que aparece nas teses remete claramente à presença das teorias evolucionistas, sendo, portanto, uma etapa do desenvolvimento humano que, também subdividida em fases, merece uma atenção mais detalhada para cada um de seus períodos.

Os higienistas demonstram também preocupações sociais e verificam que ações como a de retirar as crianças das Casas de Expostos e confiá-las a amas podem ter resultados negativos, decorrentes da necessidade financeira ou da busca de recursos de forma mais fácil. Por estes motivos, a existência das Casas era defendida por boa parte dos médicos. Apesar da condenação moral da mulher que abandonava seu filho, a Higiene despontava como o instrumento capaz de tornar aquele tipo de instituição um estabelecimento adequado à criação dos expostos.

Na verdade, porém, não é apenas o corpo infantil que ganha nova conotação e recebe maiores cuidados. Complementando esse corpo está a "alma" ou "mente" da criança, que deve ser educada com vistas ao melhor futuro da Nação. Ela aparece, então, como uma versão em miniatura do adulto, aberta a todas as impressões do mundo externo, sendo o período de transformações biológicas que caracteriza a puberdade o auge desta relação com o exterior, quando os vícios poderiam aflorar com maior intensidade.

Percebemos ainda a presença constante e crescente do paradigma científico, que se apresenta inclusive como cerne da campanha pró-aleitamento materno. No entanto, concomitantemente a esse discurso "racional" da ciência, figuram ainda resquícios da influência católica, que fundamentam alguns (pré) conceitos dos médicos principalmente com relação ao status moral da mulher, uma eterna Eva que abriga, em sua natureza pecadora, a responsabilidade pelos pecados masculinos.

Assim, curiosamente, temos, para além do retrato infantil, a imagem da mulher no final do século XIX e início do XX. Ou seja, parece que o discurso médico que ajuda a criar uma determinada imagem de infância passava necessariamente pela mãe e pela ama, cultivando não apenas a criança saudável, mas também o amor maternal e a harmonia familiar através de nova imagem feminina.

\section{REFERÊNCIAS}

Arantes, E. (1995). "Rostos de crianças no Brasil". Em F. Pilotti \& I. Rizzini (Orgs.), A arte de governar crianças: a história das políticas sociais, da legislação e da assistência à infância no Brasil (pp. 169-220). Rio de Janeiro: Instituto Interamericano Del Nino/Editora Universitária Santa Úrsula/Annais.

Armonde, A. F. N. (1874). Da educação physica, intellectual e moral da mocidade no Rio de Janeiro e de sua influência sobre a saúde. Tese de Doutorado Não-Publicada, Typ. do Apostolo, Faculdade de Medicina do Rio de Janeiro, Rio de Janeiro.

Carneiro, G. (2000). Um compromisso com a esperança: história da Sociedade Brasileira de Pediatria, 1910-2000. Rio de Janeiro: Expressão e Cultura.

Costa, J. F. (1999). Ordem médica e norma familiar (4a ed.). Rio de Janeiro: Graal.

Del Priore, M. (2000). O cotidiano da criança livre no Brasil entre a colônia e o império. Em M. Del Priore (Org.), História das crianças no Brasil (pp. 84-106). São Paulo: Contexto.

Díaz, E. (1996). La ciência y el imaginário social. Buenos Aires: Biblos.

Duque, F. B. (1864). Hygiene da criança, do nascimento á queda do cordão umbilical. Tese de Doutorado NãoPublicada, Typ. Unniversal de Laemmert, Faculdade de Medicina do Rio de Janeiro, Rio de Janeiro.

Durand, G. (1998). O imaginário. Ensaio acerca das ciências e da filosofia da imagem. Rio de Janeiro: Difel.

Fernandes, M. G. (1903). Da educação sob o ponto de vista da hygiene pedagógica. Tese de Doutorado Não-Publicada, Typ. Altina de Paulo Souza \& Cia. Faculdade de Medicina do Rio de Janeiro, Rio de Janeiro.

Kuhn, T. (1997). A estrutura das revoluções científicas. São Paulo: Perspectiva.

Lima, L. A. F. S. S. (1927). Higiene mental e educação. Tese de Doutorado Não-Publicada, Tipografia do Jornal do Commercio, Faculdade de Medicina do Rio de Janeiro, Rio de Janeiro. 
Machado, J. M. (1875). Da educação physica, intellectual e moral da mocidade no Rio de Janeiro e de sua influencia sobre a saúde. Tese de Doutorado Não-Publicada, Typ. de G. Leuzinger e Filhos, Faculdade de Medicina do Rio de Janeiro, Rio de Janeiro.

Martins, J. V. (1882). Hygiene da primeira infância. Tese de Doutorado Não-Publicada, Typ. e Lithografia de Moreira, Maximeno e C., Faculdade de Medicina do Rio de Janeiro, Rio de Janeiro.

Massimi, M. (1990). História da psicologia brasileira: da época colonial até 1934. São Paulo: E.P.U.

Mello, J. P. (1846). Acerca a educação physica dos meninos. Tese de Doutorado Não-Publicada, Typ. Teixeira e Cia., Faculdade de Medicina do Rio de Janeiro, Rio de Janeiro.

Pacheco \& Costa, T. J. X. P. (1840). Considerações geraes sobre os cuidados que se devem prestar a os recemnascidos quando vemos no estado de saude, e sobre as vantagens do aleitamento maternal. Tese de Doutorado Não-Publicada, Typografia Franceza, Faculdade de Medicina do Rio de Janeiro, Rio de Janeiro.

Pederneira, M. V. P. (1855). Que regimen será mais conveniente a creação dos expostos da Santa Casa de Misericórdia, attentas nossas circunstancias especiaes: a creação em comum dentro do Hospício, ou a privada em casas particulares? Tese de Doutorado Não-Publicada, Empreza Typ. Dous de Dezembro de Paula Brito, Faculdade de Medicina do Rio de Janeiro, Rio de Janeiro.

Sanchis, J. F. P. (2000/outubro). A igreja católica no Brasil e a dimensão do "sujeito". Trabalho apresentado em Seminário do PSICORIO, Rio de Janeiro.

Santos, J. V. (1858). Que regimen será mais conveniente para a creação dos expostos da Santa Casa de Misericórdia...? Tese de Doutorado Não-Publicada, Tip. de J. X. de Souza
Menezes, Faculdade de Medicina do Rio de Janeiro, Rio de Janeiro.

Santos, L. D. (1857). Que regimen será mais conveniente para a creação dos expostos da Santa Casa de Misericórdia, attentas nossas circunstancias especiaes: a criação em comum dentro do Hospício, ou a privada em casas particulares? Tese de Doutorado Não-Publicada, Typ. Unniversal de Laemmert, Faculdade de Medicina do Rio de Janeiro, Rio de Janeiro.

Schwarcz, L. M. (1993). O espetáculo das raças: cientistas, instituições e questão racial no Brasil - 1870 - 1930. São Paulo: Cia das Letras.

Ubatuba, M. P. S. (1845). Algumas considerações sobre a educaçam physica. Tese de Doutorado Não-Publicada, Programa de Pós-Graduação em Medicina, Typ. Commercial de E. C. do Santos, Rio de Janeiro.

Veiga Sobrinho, E. F. da. (1886) Das condições que explicam a mortalidade das crianças na cidade do Rio de Janeiro. Tese de Doutorado Não-Publicada, Typ. da "Província de Minas", Faculdade de Medicina do Rio de Janeiro, Rio de Janeiro.

Recebido em 27/07/2004 Aceito em 28/02/2005

Endereço para correspondência: Ana Maria Jacó-Vilela. Programa de Estudos e Pesquisas em História da Psicologia, ClioPsyché, Rua São Francisco Xavier, 524, $10^{\circ}$ andar, sala 10.120F. CEP 20559-900, MaracanãRJ. E-mail: cliopsyc@uerj.br 